\title{
Interproximal Reduction: A Twin Helix Device
}

\author{
${ }^{1}$ Neeraj E Kolge, ${ }^{2}$ Vivek J Patni, ${ }^{3}$ Ravindranath VK, ${ }^{4}$ Divij Joshi, ${ }^{5}$ Amol Mhatre, ${ }^{6}$ Swapnagandha R Kate
}

\begin{abstract}
Introduction: Interproximal enamel reduction dates back to 1944 when it was first advocated for correcting lack of tooth size harmony by stripping the proximal surfaces of the mandibular anterior segment. Despite convincing results, interproximal reduction (IPR) only became popular after the advent of bonding, as full-arch banding done previously completely deferred the use of this method for tooth material reduction. With the current status and ongoing development of new techniques of IPR, use of this method as a mean of gaining space has increased exponentially over the last three decades.
\end{abstract}

Procedure: A 12 -inch length of 0.036 " diameter wire is used for fabrication of the assembly. Helices of $2.5 \mathrm{~mm}$ diameter with two coils and the other according to finger grip are fabricated, and U-loops are prepared at the free ends for engaging the proximal strips. This assembly can be placed intraorally in the interdental region of our choice to cut the tooth material.

Conclusion: This assembly provides an effective grip rather than using hand held strips. It is also accessible in both anterior and posterior regions with a minimum requirement of armamentarium and can be sterilized and reused.

Keyword: Crowding, IPR, Slenderization, Twin Helix,

How to cite this article: Kolge NE, Patni VJ, Ravindranath VK, Joshi D, Mhatre A, Kate SR. Interproximal Reduction: A Twin Helix Device J Contemp Dent 2018;8(2):112-114.

Source of support: Nil

Conflict of interest: None

\section{INTRODUCTION}

Various terms are used for the procedure of reduction of interproximal tooth material which in turn helps in attaining a good alignment and long-term stability of treatment goals. They are as follows:

- Interproximal enamel reduction ${ }^{1}$

- Air-rotor stripping ${ }^{2}$

- Slenderizing $^{3}$

- Reproximation $^{4}$

\footnotetext{
${ }^{1,6}$ Postgraduate Student, ${ }^{2}$ Professor, ${ }^{3}$ Professor and HOD, ${ }^{4}$ Senior Lecturer, ${ }^{5}$ Associate Professor

${ }^{1-6}$ Department of Orthodontics and Dentofacial Orthopedics, MGM Dental College and Hospital, Kamothe, Navi Mumbai, Maharashtra, India
}

Corresponding Author: Neeraj E Kolge, Department of Orthodontics and Dentofacial Orthopedics, MGM Dental College and Hospital, Navi Mumbai, Maharashtra, India, e-mail: neerajkolge11@gmail.com

\section{Historical Background}

Interproximal reduction (IPR) dates back to 1944, when it was first advocated for correcting lack of tooth size harmony by stripping the proximal surfaces of the mandibular anterior segment. ${ }^{5} \mathrm{~A}$ few years later, the detailed technique was described followed by appropriate guidelines for remineralization of enamel. ${ }^{6}$ Increased posttreatment stability was also attributed when IPR was combined with circumferential supracrestal fiberotomy. ${ }^{7}$

Despite convincing results, IPR only became popular after the advent of bonding, as full-arch banding done previously completely deferred the use of this method for tooth material reduction. It was in mid 80s when ARS technique attracted orthodontists globally and soon became a viable method for space gaining in mild to moderate crowding cases as an alternative to expansion or extraction. 8,9

It was also used as a method to improve gingival esthetics by eliminating black triangles. ${ }^{10}$ With the current status and ongoing development of new techniques of IPR, use of this method as a mean of gaining space has increased exponentially over the last three decades. ${ }^{11}$

\section{PROCEDURE}

- A 12-inch length of 0.036 " diameter wire is used for fabrication of the assembly.

- Bending of helices (Figs. 1A and B) is followed by $90^{\circ}$ vertical bends are given on either side of the horizontal arm at the free ends of the wire (Fig. 2).

- U-loops are prepared at the free ends for engaging the proximal strips, and the excess wire is cut.

- The vertical arms are activated by approximately $10^{0}$ (Fig. 3), and a proximal strip is engaged. This helps in keeping the proximal strip taut.

- $2.5 \mathrm{~mm}$ radius helix (with two coils) is made at one end of the wire while a helix with a diameter approximating the finger grip (Figs. 4 and 5) is made at the other end.

- Assembly (Fig. 6) can be placed intraorally in the interdental region of our choice to reduce the tooth material (Figs. 7A and B).

\section{Advantages}

- More effective than using loose hand-held strips.

- Accessibility in both anterior and posterior regions. 


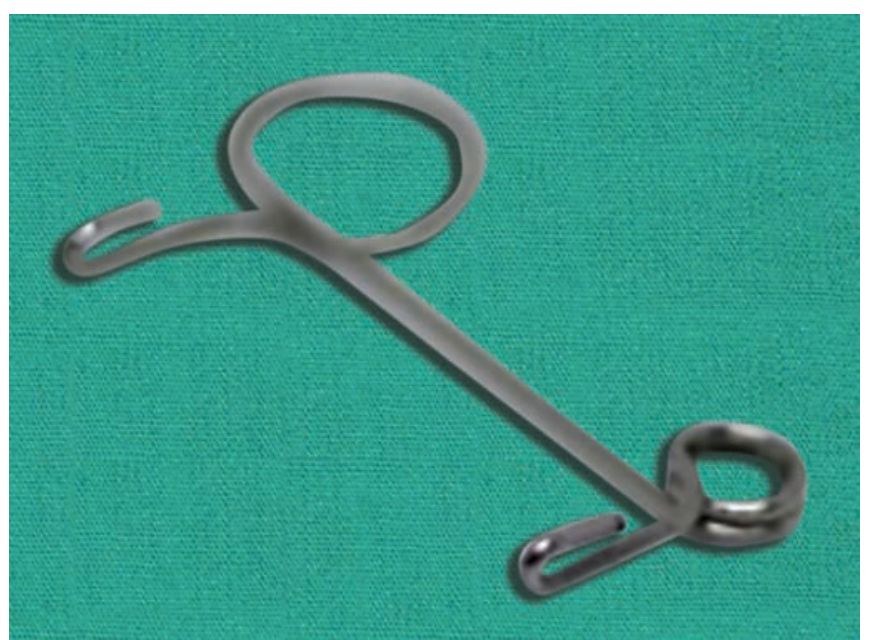

Fig. 1A: Fabrication of helices (small)

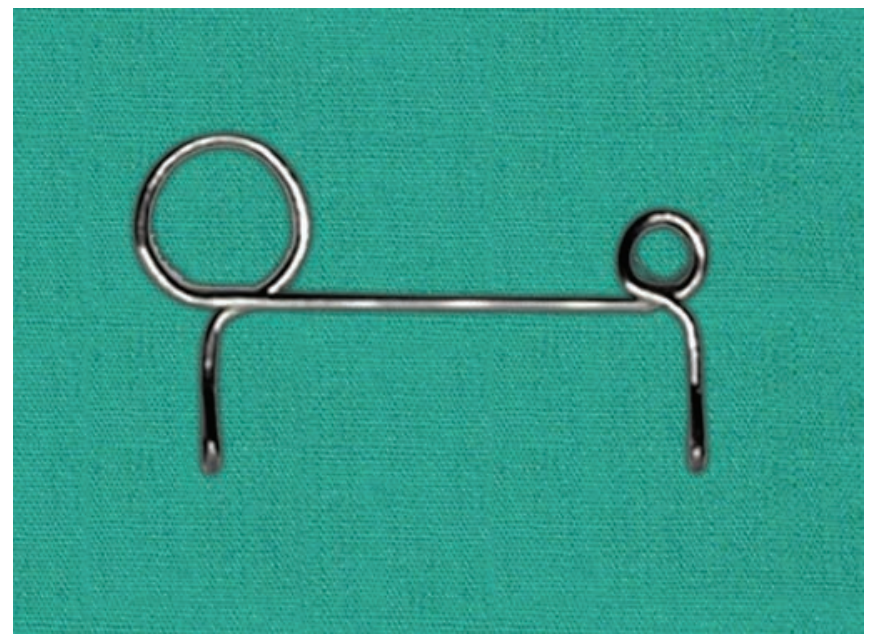

Fig. 2: Assembly with arms in passive form

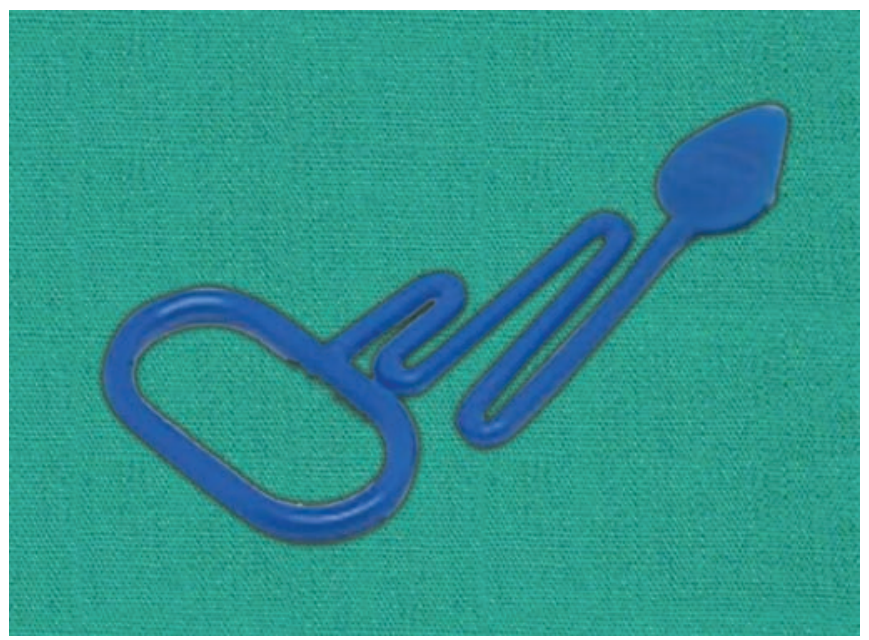

Fig. 4: Finger grip

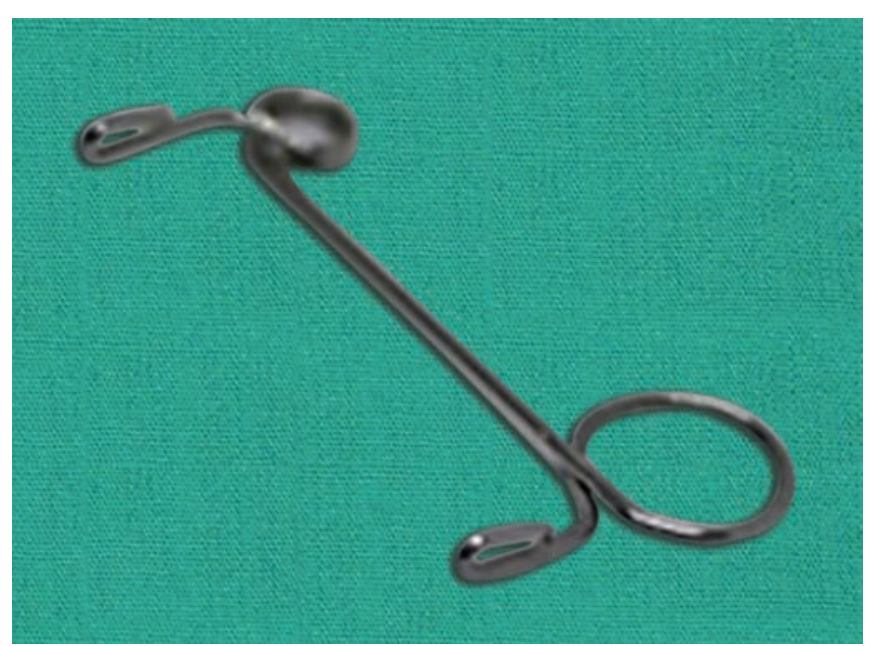

Fig. 1B: Fabrication of helices (large)

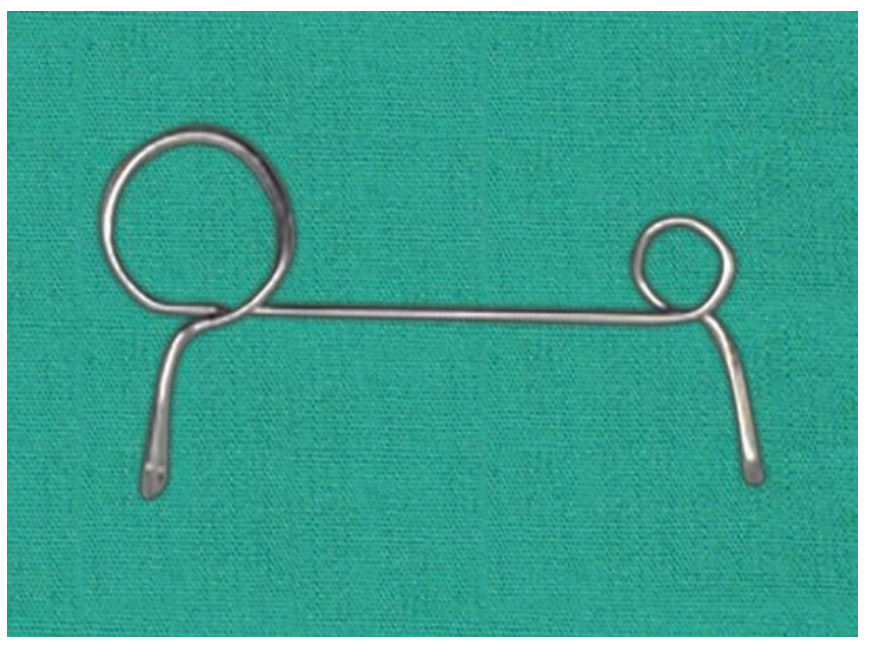

Fig. 3: Activation of free arms

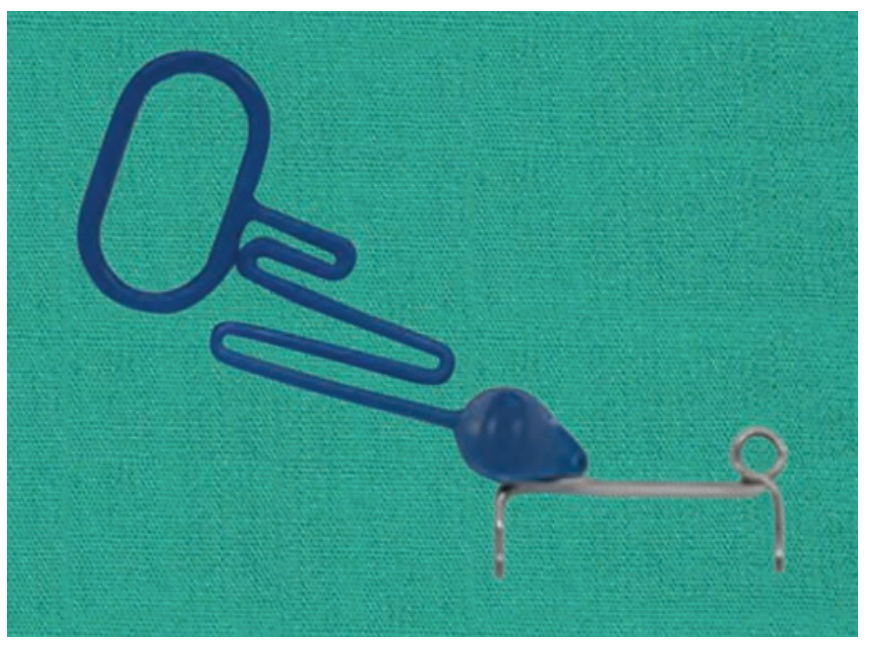

Fig. 5: Engaging the finger-grip 


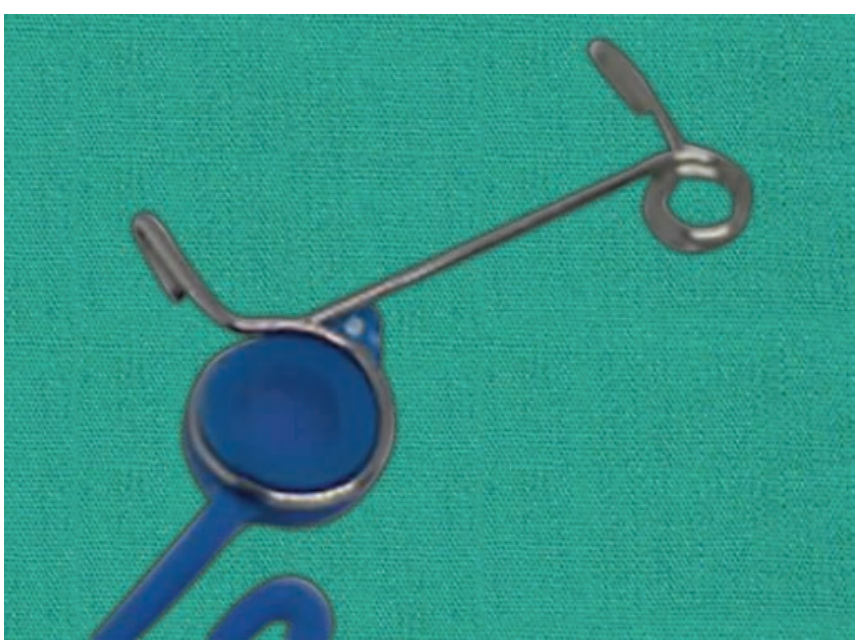

Fig. 6: Twin helix device with the finger grip

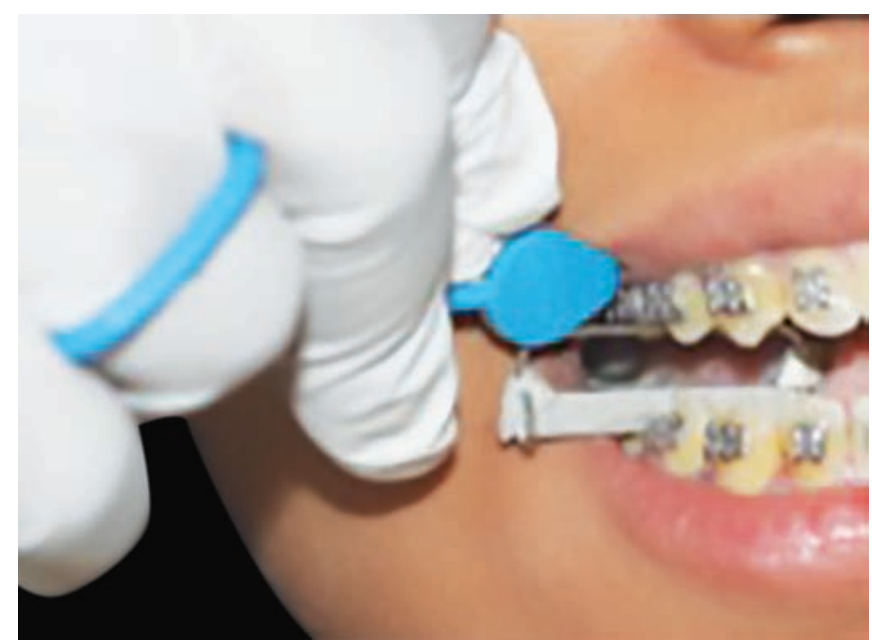

Fig. 7A: Assembly placed intraorally (posterior)

- Minimum armamentarium required

- Can be sterilized and re-used

- Amount of proximal strip wastage is minimal

- Time-saving

- Economical

\section{CONCLUSION}

Thus, this is an efficient, effective and economical tool for inter-proximal reduction.

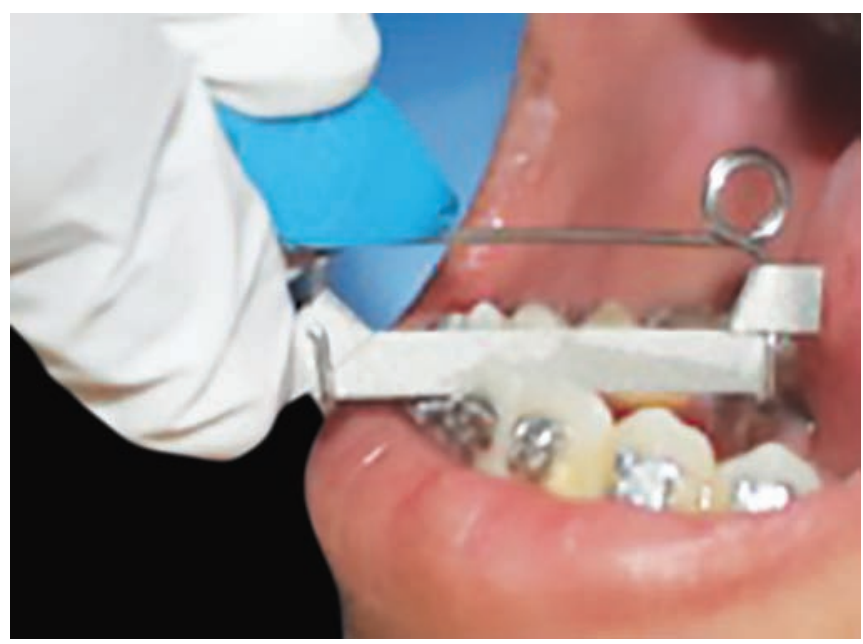

Fig. 7B: Assembly placed intraorally (anterior)

\section{REFERENCES}

1. Zachrisson BU, Nyøygaard L, Mobarak K. Dental health assessed more than 10 years after interproximal enamel reduction of mandibular anterior teeth. Am J Orthod Dentofac Orthop 2007;131:162-169.

2. Sheridan JJ. Air-rotor stripping. J Clin Orthod 1985;19:43-59.

3. Broadbent JM. Recontouring teeth for excellence in orthodontic case finishing. Part I: Section Two \& Three. Air-rotor Slenderizing (ARS). Funct Orthod 1992; 9: 4-6,8-16,8-24.

4. Peck H, Peck S. An index for assessing tooth shape deviations as applied to the mandibular incisors. Am J Orthod 1972;61:384-401.

5. Ballard ML. Asymmetry in tooth size: A factor in the etiology, diagnosis, and treatment of malocclusion. Angle Orthod 1944;14:67-71.

6. Hudson AL. A study of the effects of mesio-distal reduction of mandibular anterior teeth. Am J Orthod 1956; 42: 615-24.

7. Boese LR. Fiberotomy and reproximation without lower retention, nine years in retrospect: Part II. Angle Orthod 1980;50:88-97.

8. Sheridan JJ. Air-rotor stripping. J Clin Orthod 1985; 19:43-59.

9. Sheridan JJ. Air-rotor stripping update. J Clin Orthod 1987; 21:781-788.

10. Zachrisson BU. Interdental papilla reconstruction in adult orthodontics. World J Orthod 2004;5:67-73.

11. Keim RG, Gottlieb EL, Nelson AH, Vogels DS. Study of Orthodontic Diagnosis and Treatment Procedures Part 1: Results and Trends. J Clin Orthod 2008;42:625-640. 